\title{
THEORETIC-EXPERIMENTAL EVALUATION OF A CASCADE REFRIGERATION SYSTEM FOR LOW TEMPERATURE APPLICATIONS USING THE PAIR R22/R404A
}

\author{
J. J. Fiori ${ }^{\mathrm{a}}$, \\ C. U. S. Limab, \\ and V. Silveira Junior ${ }^{a}$ \\ ${ }^{a}$ Universidade Estadual de Campinas \\ Faculdade de Engenharia de Alimentos \\ Departamento de Engenharia de Alimentos \\ Campinas, São Paulo, Brasil \\ jufiori@fea.unicamp.br \\ ${ }^{\mathrm{b}}$ Universidade Federal do Pará \\ Instituto de Tecnologia \\ Faculdade de Engenharia Mecânica \\ Belém, Pará, Brasil
}

\section{ABSTRACT}

This paper presents a thermodynamic analysis of a cascade refrigeration system using the refrigerant R22 as the working fluid in the high temperature circuit (HT) and the refrigerant R404a as the working fluid in the low temperature circuit (LT). The present analysis aimed to obtain the condensing temperature of the LT that provides an optimal value for the coefficient of performance (COP) of the cycle. Parameters involved in the analysis included the evaporation temperature, the condensing temperature and the difference between the condensing temperature of the LT ( $\left.\mathrm{T}_{\mathrm{C} \_ \text {LT }}\right)$ and evaporation temperature of the HT $\left(\mathrm{T}_{\mathrm{E}} \mathrm{HT}\right)-\Delta \mathrm{T}_{\mathrm{CAS}}$. Simulations were performed using the software EES (Engineering Equation Solver). In addition to the analysis, experimental data obtained from a prototype was compared with the simulated results which showed good agreement. The COP varies with the increase in the intermediate temperature; however this variation does not exceed $1 \%$.

Keywords: refrigerating system; compression system; cascade system; R22; R404a

\section{NOMENCLATURE}

COP Coefficient of performance

GWP Global Warming Potential

$\mathrm{h} \quad$ Specific enthalpy, $\mathrm{kJ} \mathrm{kg}^{-1}$

HT High Temperature Circuit

LT Low Temperature Circuit

$\dot{m} \quad$ Mass flow, $\mathrm{kg} \cdot \mathrm{s}^{-1}$

ODP Ozone Depletion Potential

$\mathrm{P} \quad$ Pressure, $\mathrm{kPa}$

Q Heat rate, $\mathrm{kW}$

s $\quad$ Specific entropy, $\mathrm{kJ} \cdot \mathrm{kg}^{-1} \cdot \mathrm{K}^{-1}$

$\mathrm{T}$ Temperature, ${ }^{\circ} \mathrm{C}$ or $\mathrm{K}$

TR Tons of Refrigeration, equivalent to $3500 \mathrm{~kW}$

\section{Greek symbols}

$\eta \quad$ yield

$\Delta \mathrm{T}_{\mathrm{CAS}}=\mathrm{T}_{\mathrm{C}_{-} \mathrm{LT}}-\mathrm{T}_{\mathrm{E}_{-} \mathrm{HT}}$, temperature difference in the cascade

\section{Subscripts}

C condensing

CAS cascade heat exchanger

E evaporating

G global

$\mathrm{H}$ related to HT

I water intake (condenser)

L related to LT

$\begin{array}{ll}\mathrm{M} & \text { mechanical } \\ \mathrm{O} & \text { water outlet (condenser) } \\ \mathrm{S} & \text { isentropic }\end{array}$

\section{INTRODUCTION}

The cascade refrigeration cycle is generally used in operations that have a high difference between condensing and evaporation temperatures. In this case, the use of a single-stage cycle becomes problematic since the discharge temperature of the compressor is considerably high. The rise in refrigerant temperature, especially at the point of discharge, creates compressor lubrication problems, since high temperatures cause carbonization of lubricating oil and, consequently, irreversible damage to the compressor. Another recurrent problem is the reduction in volumetric efficiency of the compressor, especially the alternative compressors, since this characteristic directly depends on the compression ratio which is thus related to the evaporation and condensing temperatures. The cascade system allows the utilization of two separate single-stage cycles, with different refrigerants exchanging heat at intermediate heat exchanger, so a smaller difference in condensing and evaporation temperatures is observed. This versatility practically solves the problems mentioned above.

Considering that the scientific literature shows a centralization in works involving $\mathrm{CO}_{2}$, in this study, 
the authors aimed to study a pair of alternative refrigerants, in order to submit new data and contribute to cascade applications. The objective of this study was to evaluate the theoretical performance of a cascade refrigeration system with the pair $\mathrm{R} 22 / \mathrm{R} 404 \mathrm{a}$ and to compare the results of thermodynamic analysis performed in ESS with empirical data obtained from an experimental apparatus.

\section{THEORY}

A characteristic of cascade systems is the proper selection of refrigerants involved in the cycles. This selection ensures a high coefficient of performance for the overall cycle, combined with adequate effects of pressure, also confirming that the pressure inside the refrigerant line, in both high and low temperature cycles, and the atmospheric pressure have a favorable relationship. Thus, systems are composed of lightweight and efficient structures, with thin and low cost piping (Stoecker and Jabardo, 2002).

Another aspect to be considered in the selection of refrigerants regards environmental regulations established by the Montreal Protocol. Some chlorofluorocarbon refrigerants (CFC) strongly attack the atmospheric ozone layer and thus the production and use of chlorofluorocarbons has been sharply reduced in recent years. Other refrigerants are still tolerated, like $\mathrm{HCFC} / \mathrm{HFC} / \mathrm{FC}$, such as refrigerants R22 and R404a, because their effect is less devastating. The current trend is for the use of natural refrigerants such as ammonia, carbon dioxide, hydrocarbons, water etc. In Brazil, there are many commercial and industrial applications that use refrigerants R22 and R404a, which justifies the support of researching and searching of solutions that can contribute to better operation and performance of the facilities.

Some researchers are in favor of the use of ammonia, $\mathrm{NH}_{3}$ (R717), as refrigerant, in part because it is "natural" and less aggressive to the ozone layer, thus having less effect as a greenhouse gas. Although it has very favorable thermodynamic properties, this substance also has some undesirable characteristics, such as its pungent odor, flammability risk when mixed with air, the high toxicity and the possibility for contaminating products with which it enters contact (Stoecker and Jabardo, 2002). Moreover, at temperatures below $-35{ }^{\circ} \mathrm{C}$, its pressure is less than atmospheric pressure causing the risk of air intake (Bhattacharyya et al., 2005). Currently, ammonia is predominantly used in facilities with capacity greater than 100 TR in which the presence of a skilled professional is essential. In some cases, the use of ammonia in plants of medium capacity is allowed, with the application of a secondary fluid. In this case, the refrigeration plant is confined in the machine room, away from the products, thus reducing the risks of its use.
Another natural refrigerant that has received considerable attention in recent years is carbon dioxide, $\mathrm{CO}_{2}$ (R744). According to Yamaguchi et al (2011), $\mathrm{CO}_{2}$ is abundant and of low cost, has ODP equal to zero and low GWP, it is non-toxic, nonflammable and inert. Moreover, it presents thermodynamic and transport properties favorable for its use as a refrigerant because of its heat transfer characteristics. The use of $\mathrm{CO}_{2}$, however, is restricted to the temperature of its triple point $\left(-56.6^{\circ} \mathrm{C}\right)$. In addition, the critical temperature of the $\mathrm{CO}_{2}$ is 31.1 ${ }^{\circ} \mathrm{C}$, which is very low compared to most refrigerants. This feature requires the adoption of a transcritical cycle. Another drawback to be pointed is the pressure range normally used in condensation, which is above 80 bar.

One solution often used is the applications of transcritical $\mathrm{CO}_{2}$ associated with ammonia in a high temperature cycle. Performance of the cascade refrigeration systems involving ammonia and carbon dioxide has been studied by several publications in recent years. Dopazo and Fernández-Seara (2011) developed a prototype cascade refrigeration system using ammonia and carbon dioxide as high and low temperature refrigerants, respectively. This system studied is equipped with a frequency converter on the low temperature compressor and a refrigerant bypass for the high temperature compressor. With these devices, it was possible to control the evaporation temperature and the temperature difference in the intermediate heat exchanger (cascade). The condensing temperature was controlled by the flow of cooling water applied to the condenser. Experimental results showed that the overall COP is a function of the applied intermediate temperature, presenting a maximum point at the optimal temperature and decreasing as the temperature increases.

Getu and Bansal (2008) presented the results of a theoretical study involving the simulation of a cascade cycle in which several pairs of refrigerants were evaluated. The researchers established $\mathrm{CO}_{2}$ as the LT fluid and simulated various refrigerants in the HT. Simulation results showed that ethanol has the best performance, followed by ammonia, propane and R404a. The authors used the software EES (Engineering Equation Solver) to perform the simulations. Factors such as evaporation and condensing temperature, temperature difference, superheat, subcooling and type of refrigerant were used to evaluate the COP of the cycle. The results are consistent with those reported by Fernández-Seara and Dopazo (2011), in which the COP is at its highest as the $\mathrm{T}_{\mathrm{C}_{\mathrm{L} T}}$ varies positively. The authors also included a multilinear regression analysis in which they obtained correlations to optimal $\mathrm{T}_{\mathrm{C}_{\mathrm{L}} \mathrm{LT}}$ and COP as a function of parameters such as evaporation and condensing temperatures, superheating, subcooling and $\Delta \mathrm{T}_{\mathrm{CAS}}$.

Lee et al. (2006) published the results of simulations involving the refrigerants $\mathrm{CO}_{2}$ and $\mathrm{NH}_{3}$ 
as working fluids of a cascade refrigeration cycle. Simulation results were compared with experimental results available in literature considering the same refrigerants and the same test conditions. The simulated and experimental data showed good agreement. The observed errors were attributed to the characteristics of the compressor used in the experiments. Test conditions and simulations were: $\mathrm{T}_{\mathrm{E} \_\mathrm{LT}}=-50{ }^{\circ} \mathrm{C}$, condensing temperature of the HT $\mathrm{T}_{\mathrm{C}_{-} \mathrm{HT}}=35{ }^{\circ} \mathrm{C}$ and $\Delta \mathrm{T}_{\mathrm{CAS}}=5{ }^{\circ} \mathrm{C}$. In the referenced paper the authors presented correlations to optimal $\mathrm{T}_{\mathrm{C}_{-} \mathrm{LT}}$ and COP, where COP is a function of evaporation and condensing temperatures and $\Delta \mathrm{T}_{\mathrm{CAS}}$.

Bhattacharyya et al. (2005) used the combination of $\mathrm{CO}_{2} / \mathrm{C}_{3} \mathrm{H}_{8}$ as working fluids in a cascade refrigeration cycle, being $\mathrm{CO}_{2}$ at high temperature and $\mathrm{C}_{3} \mathrm{H}_{8}$ at low temperature. The authors reported that this is a better alternative when the system also uses the high temperature side. This configuration permits a wide range of applications, both in high and low temperature. Both refrigerants are natural and have zero ODP and GWP near zero. The authors stated that the greatest advantage of using propane over ammonia is its non-toxicity. In relation to flammability, this can be solved by applying propane in the LT. They call attention to the fact that propane can be used at low temperatures ($30{ }^{\circ} \mathrm{C}$ to $-60{ }^{\circ} \mathrm{C}$ ) and, unlike ammonia, it presents pressures greater than atmospheric. The main focus of the study was to maximize the COP of the system, considering the parameters of: temperature of source and sink, temperature of coolant on condenser inlet and outlet, isentropic efficiency of the compressors, heat exchanger effectiveness, and difference in intermediate temperature, among others. The results showed that as the $\mathrm{T}_{\mathrm{C}_{-} \mathrm{LT}}$ increases, the COP also increases, experiences a maximum and then tends to fall. This trend is consistent with several other works referenced. The results also showed that the COP decreases markedly with both $\Delta \mathrm{T}_{\mathrm{CAS}}$ and the difference between the evaporation temperature and the temperature of the cooled environment

Bingming et al. (2009) presented experimental results of an analysis of a cascade refrigeration system using $\mathrm{CO}_{2}$ and $\mathrm{NH}_{3}$ refrigerants. For evaluation of the COP, the following parameters were considered: $\mathrm{T}_{\mathrm{E}_{\mathrm{LT}},}, \mathrm{T}_{\mathrm{C}_{\mathrm{L}} \mathrm{T}}, \Delta \mathrm{T}_{\mathrm{CAS}}$ and $\mathrm{LT}$ superheat. Analysis results showed that increasing $\Delta \mathrm{T}_{\mathrm{CAS}}$ strongly decreases the COP and that this decay is greater the higher the value of $\Delta \mathrm{T}_{\mathrm{CAS}}$. Regarding the degree of $\mathrm{CO}_{2}$ superheating, results showed that variation of this parameter little affects the COP. As superheating increased from $10{ }^{\circ} \mathrm{C}$ to $23{ }^{\circ} \mathrm{C}$, the COP decreased less than $3 \%$. The authors used the experimental data to test the correlations published by Lee et al. (2006) and Dopazo et al. (2007). In the first work, the simulation showed a maximum deviation of $10.2 \%$, while for the second, the gap reached a value greater than $60 \%$.
Di Nicola et al. (2005) simulated $\mathrm{CO}_{2} / \mathrm{HFCs}$ blends in cascade systems. The purpose was to obtain evaporating temperatures lower than the $\mathrm{CO}_{2}$ triple point $(216.58 \mathrm{~K})$. Ammonia was used as the working fluid of the HT and the blends tested were: R744/R125, R744/R41, R744/R32 and R744/R23. Thermodynamic properties of these blends were obtained from correlations developed with the experimental data obtained by the authors. For evaluation of the cascade system, besides COP, parameters such as temperature glide, evaporating pressure and volumetric cooling effect, which appraises the size of the compressor, were investigated. The authors concluded that the use of blends is an interesting alternative for applications in cascade refrigeration systems operating at evaporation temperatures near $200 \mathrm{~K}$.

Yamaguchi and Zhang (2009) presented the results of the evaluation of a cascade refrigeration system, utilizing $\mathrm{CO}_{2}$. In this case, the $\mathrm{HT}$ is the transcritical cycle LT is the trans-triple cycle, i.e., the evaporation temperature is below $-56.6{ }^{\circ} \mathrm{C}$. Expansion occurs in the biphasic gas-solid region with formation of dry ice inside the evaporator. Dry ice is then sublimated with the aid of an electrical resistance and the cascade system can work continuously and at stable conditions for evaporation temperatures below $-56.6^{\circ} \mathrm{C}$. The evaluation showed a COP of the system, considering heat flow in the evaporator of the LT over the power consumed in the two compressors, with a value of 1.15 .

Gong et al. (2009) designed and built an experimental apparatus to test azeotropic mixtures of R170/R23 and R170/R116. These authors were also carried out experiments involving ternary mixtures of the same refrigerants, as well as R508b (R23/R116). The aim of the work was to determine the performance of these mixtures at temperatures as low as $-80{ }^{\circ} \mathrm{C}$. The refrigerant used in the HT was maintained as R404a, and thus only the LT was evaluated. According to the authors, these mixtures are candidates to replace R508a and R508b, which are appointed as substitutes for R13 and R503 (R13/R23). The problem is that both R508a and R508b have a high GWP, justifying the search for alternatives. Tests were performed with three different condensing temperatures: $-30{ }^{\circ} \mathrm{C},-35{ }^{\circ} \mathrm{C}$ and $-40{ }^{\circ} \mathrm{C}$, and evaporation temperatures varying from $-72{ }^{\circ} \mathrm{C}$ to $-88{ }^{\circ} \mathrm{C}$. The results showed that the COP of the mixtures with R170 (ethane) always presented greater values than R508b. The R170/R116 mixture showed an increase in COP of approximately $10 \%$ compared to R508b. The cooling capacity of the mixtures was evaluated and results were compared with R508b. Mixtures of R170 showed better performance in all evaporation temperature ranges and for all condensing temperatures considered. Performance of the ternary mixture R170/R116/R23 was $40 \%$ higher than R508b. Another parameter considered in the analysis was the 
compression ratio. This parameter is directly related to the volumetric efficiency of the compressor. For all mixtures tested, R508b presented the highest compression ratio. The compression ratio of the mixture R170/R116/R23 was $10 \%$ less than that of R508B. Another factor evaluated was the compressor discharge temperature. The R170/R23 mixture showed the highest discharge temperature, about 20 $\mathrm{K}$ greater than that of R508b, while the R170/R116 mixture had the lowest discharge temperature, about $10 \mathrm{~K}$ below R508b. Given the results and considering that the GWP of R170 mixtures is $70 \%$ less than that of $\mathrm{R} 508 \mathrm{~b}$, the authors reported that such mixtures are a good alternative to cooling systems that operate in the temperature range of $-60{ }^{\circ} \mathrm{C}$ to $-80{ }^{\circ} \mathrm{C}$.

\section{SIMULATION METHOD}

In order to investigate the effect of different parameters on the COP of the cascade cycle, the ESS software was used to develop a computer routine including thermodynamic properties of refrigerants R22 and R404A.

It was evaluated the variation of the COP of the theoretical cycle for several intermediate temperatures $\left(\mathrm{T}_{\mathrm{E}-\mathrm{HT}}\right)$, implicitly assuming a fixed $\Delta \mathrm{T}_{\mathrm{CAS}}$ of $5^{\circ} \mathrm{C}$. This simulation aimed at determining the optimal intermediate temperature, in which the value of the COP is maximum.

Two additional analysis were performed: the first varying the $\mathrm{T}_{\mathrm{C} \text { HT }}$ between $30-45^{\circ} \mathrm{C}$ at $5{ }^{\circ} \mathrm{C}$ intervals; and the second by changing the $\mathrm{T}_{\mathrm{E} L T}$ between -50 to $-35{ }^{\circ} \mathrm{C}$, at $5{ }^{\circ} \mathrm{C}$ intervals. Both simulations were performed at a fixed $\Delta \mathrm{T}_{\mathrm{CAS}}=5^{\circ} \mathrm{C}$.

\section{EXPERIMENTS}

The experimental equipment of the cascade refrigeration system shown in Figure 1 and used in this study consists of two single stage refrigeration systems connected by the common heat exchanger. In this case the heat exchanger performs the role of the condenser for the LT and evaporator for the HT. The system is used for cooling a small chamber measuring $80 \times 80 \times 120 \mathrm{~cm}$. Access to the chamber is through a door equipped with a glass window through which observations can be made without opening the door.

The HT condenser operates with water, provided by a cooling tower used for water reuse. The compressors are semi-hermetic, Bock ${ }^{\mathrm{TM}}$, with motor specifications of $2.2 \mathrm{~kW}, 50 \mathrm{~Hz}$ and $380 \mathrm{~V}$, equipped with frequency converters $\mathrm{Weg}^{\mathrm{TM}}$ model CFW09 in order to allow for experimental control. The heads of both compressors are cooled with the same water used in the condenser. Thus, before returning to the cooling tower, water flows in series, initially at the head of the LT compressor and then at the head of the HT compressor.
For the circulation of water between the condenser and cooling tower a centrifugal pump driven by a $1 / 2$ HP motor was used. The HT circulates $\mathrm{R} 22$ and in the LT is R404a. Thus, the cascade system operates between the condensing temperature of the HT $\left(\mathrm{T}_{\mathrm{C}_{-} \mathrm{HT}}\right)$ and evaporation temperature of the $\mathrm{LT}\left(\mathrm{T}_{\mathrm{E} L \mathrm{LT}}\right)$. The temperature difference, $\Delta \mathrm{T}_{\mathrm{CAS}}=$ $\mathrm{T}_{\mathrm{C} \text { LT }}-\mathrm{T}_{\mathrm{E} \_\mathrm{HT}}$, is observed in the intermediate heat exchanger.

Both HT and LT circuits are equipped with temperature and pressure sensors, which permit the evaluation of the COP values. Therefore, both circuits have Pt100 temperature sensors, Novus ${ }^{\mathrm{TM}}$, at the compressor suction $\left(\mathrm{T}_{1 \_\mathrm{LT}}\right.$ and $\left.\mathrm{T}_{1 \_\mathrm{HT}}\right)$ and discharge $\left(\mathrm{T}_{2}\right.$ LT and $\mathrm{T}_{2}$ HT $)$, outlet of the liquid vessel $\left(\mathrm{T}_{3 \mathrm{LT}}\right.$ and $\left.\mathrm{T}_{3 \mathrm{HT}}\right)$ and the evaporator inlet $\left(\mathrm{T}_{4 \mathrm{LT}}\right.$ and $\left.\mathrm{T}_{4}{ }_{-} \mathrm{HT}\right)$. Additionally, pressure transducers, Novus ${ }^{\mathrm{TM}}$, with $\pm 0.32 \%$ accuracy were installed at the suction $\left(\mathrm{P}_{1 \text { LT }}\right.$ and $\left.\mathrm{P}_{1 \mathrm{HT}}\right)$ and discharge $\left(\mathrm{P}_{2 \text { LT }}\right.$ and $\left.\mathrm{P}_{2 \text { HT }}\right)$ of each compressor. From these measurements, the true state of the refrigerant at each point can be determined.

Determination of refrigerant flow in both circuits is determined indirectly. An orifice plate flowmeter is installed in the cooling water line. Based on an energy balance in the condenser, is possible to determine the refrigerant flow in the HT. Once calculated the flow in the HT, an energy balance in the intermediate heat exchanger allows for determination of the LT flow.

Control, operation and especially data acquisition of parameters, such as temperatures and pressures, are performed by a programmable logic controller (PLC), $\mathrm{HI}^{\mathrm{TM}}$, equipped with analog and digital inputs/outputs. The main goal of this device was to determine the COP of the cascade refrigeration system in steady state.

The main purpose of the experimental procedure is to maintain the evaporation condensing temperatures, considering a given load. The thermal load is provided by an electrical resistance located inside the chamber. The total power of the device is $3.8 \mathrm{~kW}$, however this power can be modified via a power inverter, Therma ${ }^{\mathrm{TM}}$.

The condensing temperature of the HT was controlled by setting the circulating water flow in the condenser. The evaporation pressure of the HT was adjusted by controlling the motor rotation of the compressor. On the other hand, evaporation temperature of the LT varied with the compressor speed as well as the thermal load provided by the electrical resistance.

The degree of superheating at the evaporator and at the intermediate heat exchanger (cascade) is guaranteed by the respective expansion valves. The degree of subcooling is determined by the temperature sensors.

Once the temperatures, pressures and flow rates stabilized, data was recorded for thirty minutes at one second intervals. 


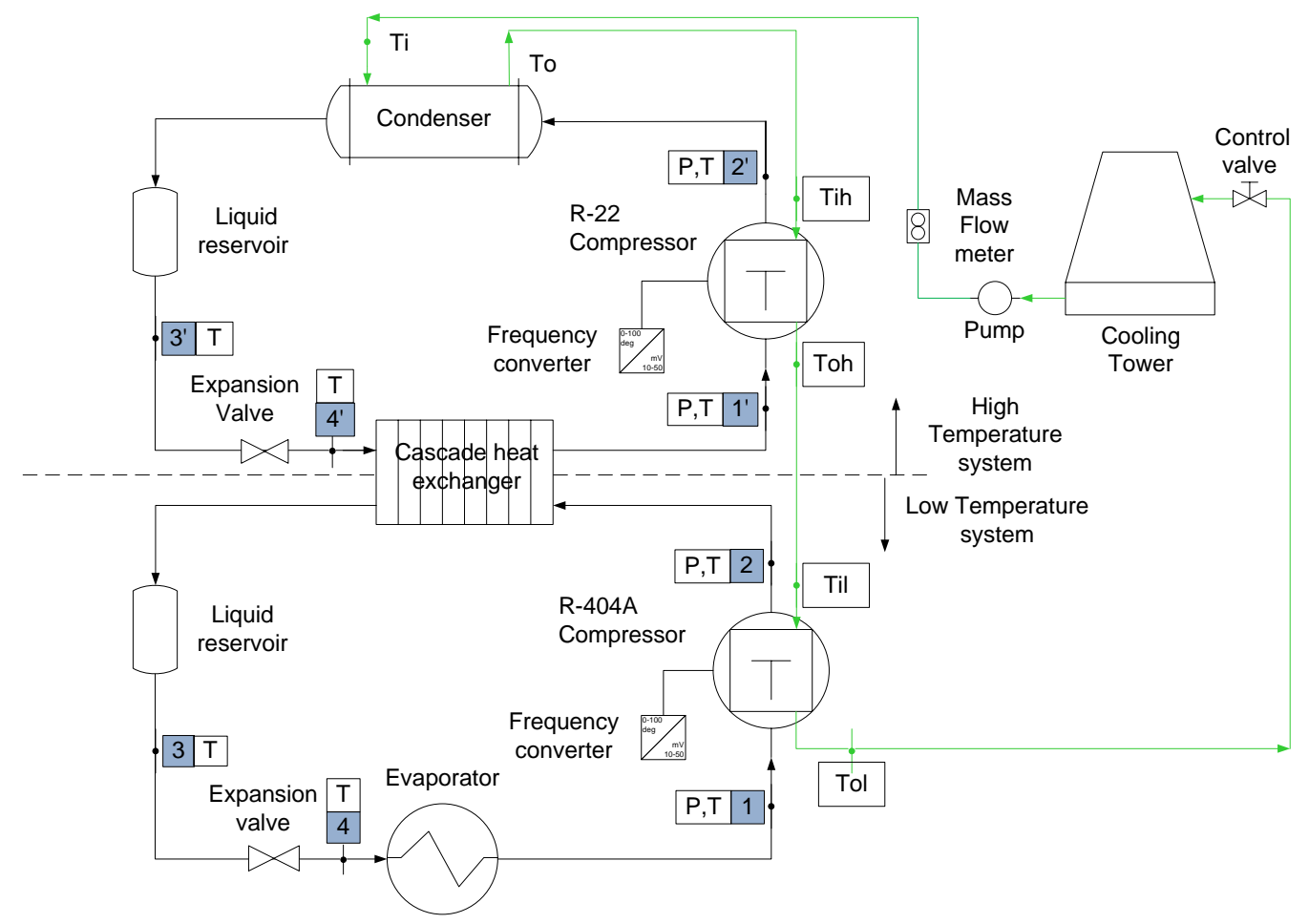

Figure 1. Schematic of the cascade refrigeration system.

As a starting point for evaluation of the experimental apparatus, a central composite design (CCD) was constructed, with three manipulated variables: rotational speed of the LT (LTS); rotational speed of the HT (HTS); and thermal load provided by additional resistance $(\mathrm{P})$ at two levels ($1,+1)$, generating eight trials, plus the addition of six axial points and three replicates at the central point, totaling 17 trials according to the methodology proposed by Rodrigues and Iemma (2009). Table 1 shows the actual values applied in the CCD. The rotation is given in revolutions per minute (rpm) and power in $\mathrm{W}$.

Table 1. Actual values used in the CCD to determine the operational conditions of the system.

\begin{tabular}{|c|c|c|c|}
\hline \multirow{2}{*}{ Levels } & \multicolumn{3}{|c|}{ Cases } \\
\cline { 2 - 4 } & LTS & HTS & P \\
\hline$-1,68$ & 850 & 850 & 0 \\
\hline-1 & 971 & 971 & 304 \\
\hline 0 & 1150 & 1150 & 750 \\
\hline+1 & 1329 & 1329 & 1196 \\
\hline$+1,68$ & 1450 & 1450 & 1500 \\
\hline
\end{tabular}

\section{NUMERICAL METHOD}

The main evaluation parameter of the cascade refrigeration system is the COP.

$$
C O P_{C A S}=\frac{Q_{e}}{W_{H T}+W_{L T}}
$$

From a simplification of the first law of thermodynamics, the COP was calculated using Equation 1. Where $Q_{e}$ is the thermal load provided by the electrical resistance added to the chamber load, $\mathrm{W}_{\mathrm{HT}}$ and $\mathrm{W}_{\mathrm{LT}}$ represent, respectively, the work of the high and low temperature compressors, and can be determined by Equations below:

$$
\begin{aligned}
& W_{H T}=\frac{\dot{m}_{H T} \cdot\left(h_{2_{-} H T}-h_{1 \_H T}\right)}{\eta_{m} \cdot \eta_{s_{-} H T}} \\
& W_{L T}=\frac{\dot{m}_{L T} \cdot\left(h_{2_{-} L T}-h_{1_{-} L T}\right)}{\eta_{m} \cdot \eta_{s_{-} L T}}
\end{aligned}
$$

In Equations (2) and (3) above, $\eta_{\mathrm{m}}$ and $\eta_{\mathrm{s}}$ represent the mechanical yields and the isentropic efficiency, respectively.

$$
\begin{gathered}
\eta_{s_{-} L T}=\frac{h_{2 s_{-} L T}-h_{1_{-} L T}}{h_{2_{-} L T}-h_{1_{-} L T}} \\
\eta_{s_{-} H T}=\frac{h_{2 s_{-} H T}-h_{1_{-} H T}}{h_{2_{-} H T}-h_{1_{-} H T}}
\end{gathered}
$$

Isentropic efficiency was calculated by equations (4) and (5).

According to Stoecker and Jabardo (2002), the mechanical efficiency of refrigeration compressors 
varies from 0.8 to 0.9 , hence the value 0.85 was adapted for the two compressors.

\section{RESULTS AND DISCUSSION}

Figures 2 to 4 highlight some of the results obtained from the simulation performed. Figure $2 \mathrm{a}$ shows the variation of the COP for the LT and HT and the overall COP considering the work of the two compressors and heat flow in the LT. Figure $2 \mathrm{~b}$ is included to emphasize the global behavior of the COP. The plots indicate that as the intermediate temperature increases, the COP of the LT decreases and the COP of the HT increases. This behavior is consistent, because the COP varies directly with the compression work. The same figure shows that the global COP (COPG) experiences an increase, reaches a maximum and then falls. This behavior is consistent with the works of Dopazo and Fernández-Seara (2011), Getu and Bansal (2008) and Lee et al. (2006).

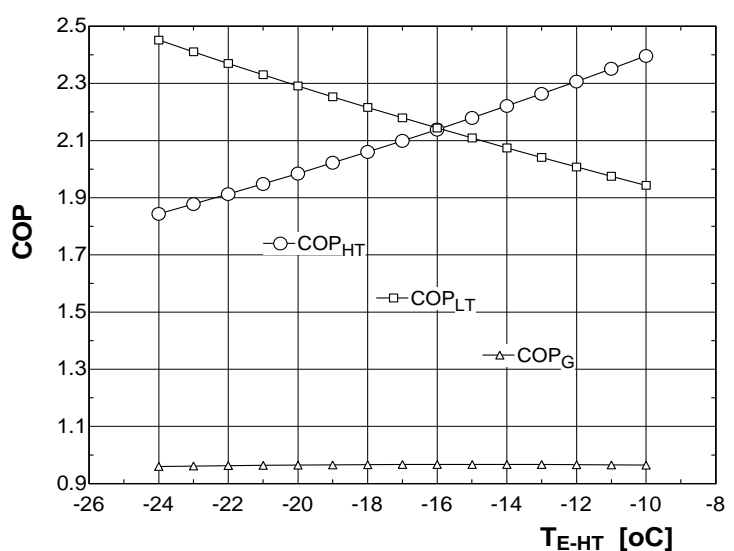

a

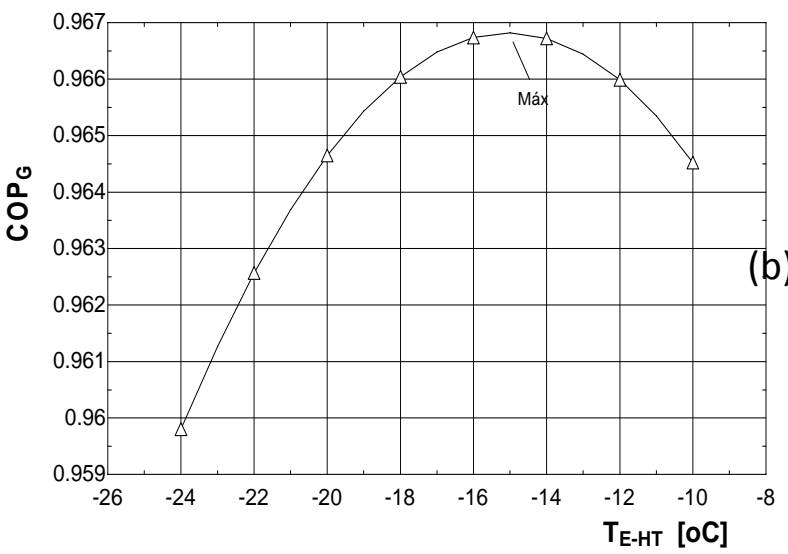

b

Figure 2. Variation of the COP with the intermediate temperature.

Figure 3 shows the influence of condensing temperature of the LT on the $\mathrm{COP}_{\mathrm{G}}$. Analyzing the plot it may be concluded that the increase in condensing temperature causes a decrease in COP. This behavior is easily explained by the increase in compressor work of the HT.

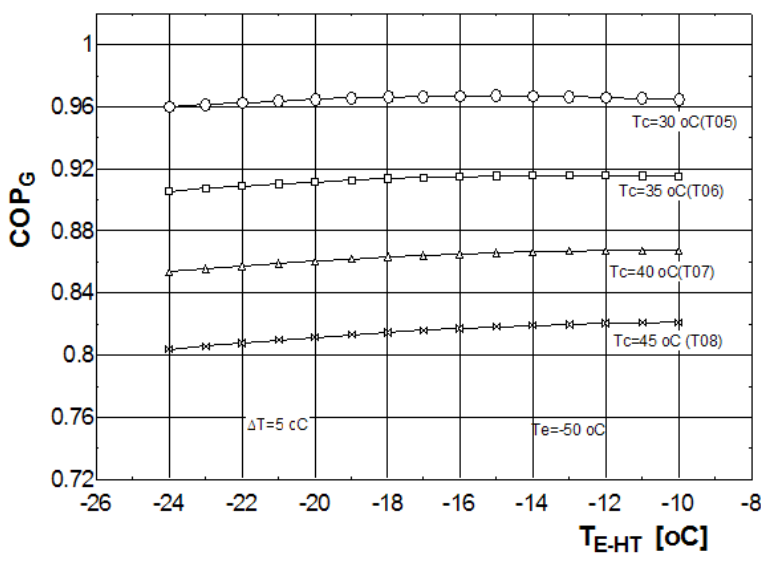

Figure 3. Influence of condensing temperature on the COP.

Finally, Figure 4 shows the effect of evaporation temperature on the COP. It can be easily seen that when the condensing temperature remains unchanged, increases in the evaporation temperature also cause a raise in the COP and vice versa, i.e., a decrease in the evaporation temperature provokes a drop in the COP of the cascade cycle. Figures 2, 3 and 4 were designed considering a temperature difference between the two circuits of $5^{\circ} \mathrm{C}$.

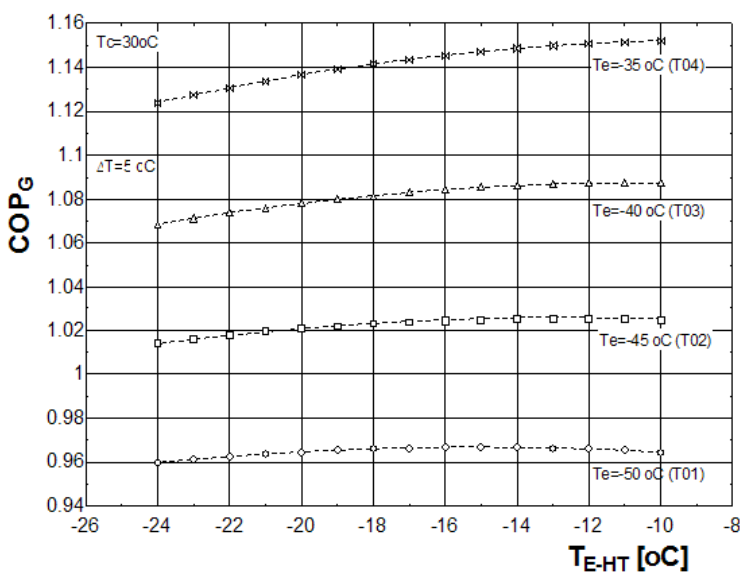

Figure 4. Influence of evaporation temperature on the COP.

According to the experimental data obtained it was possible to plot curves for the COPs for both the circuits and the overall COP. These results are shown in Figure 5, below.

For a better analysis, in Figure 5 linear regression plots were included using second degree polynomial equations for all data. These curves are used to facilitate data analysis and better visualize the tendency. Initially it is clear that, contrary to expectations, the curves for the COPs of both circuits fail to intersect as shown in Figure 2 for the performed simulations. This occurred because the 
intermediate temperature, i.e., the condensing temperature of the LT (or the evaporation temperature of the HT) assumed a very low value. Thus, it can be observed that cycles presented different COPs due to significant differences in temperature (or pressure) between condensing and evaporation. Consequently, it can be clearly observed in Figure 5 that the COP of the HT is lower than the COP of the LT, since the difference between the temperatures is higher. The opposite occurs with the LT. However also in Figure 5 it can be noted that while the trend of the COP of the HT is to increase, the contrary occurs with the COP of the LT. This clearly indicates that the increase in intermediate temperature causes intersection of the two curves, as provided by the simulation process

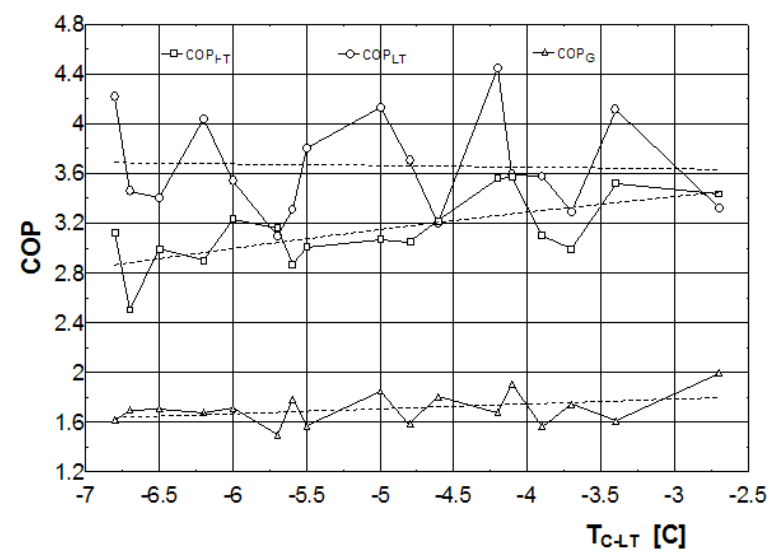

Figure 5. Experimental results for the HT, LT and global COPs.

A second important observation that can be made when analyzing Figure 5 is related to the values found for $\mathrm{COP}_{\mathrm{G}}$. The simulation results show that this parameter exhibits a curve with a maximum that occurs at the point of intersection of the curves of the separate COPs. The curve of the $\mathrm{COP}_{\mathrm{G}}$ shown in Figure 5 appears to show the upslope of the curve. That is, because the COP curves did not cross, the $\mathrm{COP}_{\mathrm{G}}$ curve presented no maximum value. A new design to obtain new experimental data and provide a higher intermediate temperature would certainly favor the collection of data according to the performed simulation

\section{CONCLUSIONS}

This article considers a theoretic-experimental evaluation of a cascade refrigeration system under steady state conditions, using R22 and R404a as the working fluid of the high and low temperature circuits, respectively. With a cascade refrigeration cycle it is possible to obtain extremely low evaporation temperatures without compromising important cycle parameters such as COP, volumetric efficiency of the compressor, discharge temperature etc.
Simulations performed showed that the COPG had a maximum value at the intersection of the COP curves of each circuit. On the other hand, from the experimental results it was not possible to obtain a curve for the maximum COPG because the intermediate temperature was very low.

The curves obtained for the each COP of the individual cycles and the COPG presented tendencies which are consistent with values obtained by simulation and also with literature. From the trends observed in the curves obtained experimentally is possible to affirm that adjustments in the equipments should confirm that the experimental equipment used in this study behaves in a manner similar to equipment cited in literature.

\section{ACKNOWLEDGEMENTS}

The authors would like to acknowledge the $\mathrm{CNPq}$ for its financial support.

\section{REFERENCES}

Bhattacharyya, S, Kumar A., Khurana R. K., and Sarkar J., 2005, Optimization of a $\mathrm{CO}_{2}-\mathrm{C}_{3} \mathrm{H}_{8}$ Cascade System for Refrigeration and Heating, International Journal of Refrigeration, Vol. 28, No. 8, pp. 1284-1292.

Bingming, W., Huagen, W., Jianfeng, L., and Ziwen, X., 2009, Experimental Investigation on the Performance of $\mathrm{NH}_{3} / \mathrm{CO}_{2}$ Cascade Refrigeration System with Twin-Screw Compressor, International Journal of Refrigeration, Vol. 32, No. 6, pp.13581365 .

Di Nicola, G., Giuliania, G., Polonaraa, F., and Stryjekb R., 2005, Blends of Carbon Dioxide and HFCs as Working Fluids for the Low-Temperature Circuit in Cascade Refrigerating Systems, International Journal of Refrigeration, Vol. 28, No. 2, pp. 130-140.

Dopazo, A., Fernández-Seara, J., Arias, A., Sieres, J., and Uhía, F., 2007, Thermodynamic Analysis of a $\mathrm{CO}_{2} / \mathrm{NH}_{3}$ Cascade Refrigeration System, in: 22nd International Congress of Refrigeration, Beijing, China, pp. 2466-2473.

Dopazo, A., Fernández-Seara, J., 2011, Experimental Evaluation of a Cascade Refrigeration System Prototype with $\mathrm{CO}_{2}$ and $\mathrm{NH}_{3}$ for Freezing Process Application, International Journal of Refrigeration, Vol. 34, pp. 257-267.

EES. Engineering Equation Solver, 2008, fChart Software Inc.

Getu, H. M., Bansal, P. K., 2008, Thermodynamic Analysis of an R744-R717 Cascade Refrigeration System, International Journal of Refrigeration, Vol. 31, pp. 45-54.

Gong, M., Sun, Z., Wu, J., Zhang, Y., Meng, C., and Zhou, Y., 2009, Performance of R170 Mixtures as Refrigerants for Refrigeration at $-80{ }^{\circ} \mathrm{C}$ 
Temperature Range, International Journal of Refrigeration, Vol. 32, No. 5, pp. 892-900.

Lee, T.-S., Liu, C.-H. and Chen, T.-W., 2006, Thermodynamic Analysis of Optimal Condensing Temperature of Cascade-Condenser in $\mathrm{CO}_{2} / \mathrm{NH}_{3}$ Cascade Refrigeration Systems, International Journal of Refrigeration, Vol. 29, No. 7, pp. 1100-1108.

Rodrigues, M. I., and Iemma, A. F., Planejamento de experimentos e otimização de processos, 2nd Edition, Campinas: Casa do Espírito Amigo Fraternidade Fé e Amor, 2009, 358 p. (in Portuguese)

Stoecker, W. F., and Jabardo, J. M. S., Refrigeração Industrial. 2nd Edition, São Paulo: Editor Edgard Blucher Ltda, 2002. (in Portuguese)

Yamaguchi, H., and Zhang, X. -R., 2009, A Novel CO2 Refrigeration System Achieved by $\mathrm{CO}_{2}$ Solid-Gas Two-Phase Fluid and its Basic Study on System Performance, International Journal of Refrigeration, Vol. 32, No. 7, pp. 1683-1693.

Yamaguchi, H., Niu, X. -D., Sekimoto, K., and Neksa, P., 2011, Investigation of Dry Ice Blockage in an Ultra-Low Temperature Cascade Refrigeration System Using CO2 as a Working Fluid. International Journal of Refrigeration, Vol. 34, No. 2, pp. 466-475.

Received: July 29, 2012

Revised: August 29, 2012

Accepted: September 29, 2012 